\title{
인공신경망 기반의 풍력발전기 발전량 예측에 관한
Study on the Prediction of wind Power Generation Based on Artificial Neural Network
}

\author{
김 세 윤*, 김 성 호 \\ (Se Yoon $\mathrm{Kim}^{1}$ and Sung-ho $\mathrm{Kim}^{1}$ ) \\ ${ }^{1}$ Kunsan National University. School of Electronic \& Information Engineering
}

\begin{abstract}
The power generated by wind turbines changes rapidly because of the continuous fluctuation of wind speed and direction. It is important for the power industry to have the capability to predict the changing wind power. In this paper, neural network based wind power prediction scheme which uses wind speed and direction is considered. In order to get a better prediction result, compression function which can be applied to the measurement data is introduced. Empirical data obtained from wind farm located in Kunsan is considered to verify the performance of the compression function.
\end{abstract}

Keywords: wind turbine, neural network, wind speed, wind direction, wind power prediction

\section{I. 서론}

최근 화석에너지의 고갈에 대비한 친환경적인 대체 에너 지원으로 풍력발전이 주목을 받고 있다. 독일, 네덜란드 및 덴마크를 중심으로 서유럽 여러 나라에서는 1970년대부터 풍력발전에 대한 많은 연구가 있어 왔고, 그 결과 최근에는 수 MW급 풍력발전 시스템을 상용화하기에 이르렀다. 국내 에서도 다수의 연구기관을 중심으로 풍력발전 시스템의 국 산화 연구개발이 활발히 진행되고 있으며 또한 정부 지원 의 지역 에너지 사업을 통해 제주도 등 다수의 지역에 중 대형 국내외 시스템이 도입되어 설치 운전되면서 국내 풍 력 자원 개발의 가능성을 검토하고 있는 실정이다.

대부분의 풍력 발전 단지(wind farm)는 수 십대의 풍력발 전기와 풍속 및 풍향의 측정을 위한 기상타워(meteorological tower)로 구성된다. 터빈 블레이드의 허브 높이에서의 풍속 은 발전 용량과 밀접한 관계를 갖으며, 초, 분, 시간 범위에 서 지속적으로 변화하게 된다. 풍력발전 단지의 설치와 관 련된 장기계획(long-tern planning)에서 풍속의 예측은 연단 위로 행해지고 있으며, 개별 풍력발전기의 제어를 위해서는 단기간(short term)의 풍속 예측이 요구된다. 특히 단기 풍속 예측은 풍력 터빈의 부하, 블레이드 피치각도의 변화 및 시 간지연을 갖는 제어 시스템의 효율적인 운영을 위해 필요 로 되며, 또한 전력 전송 스케쥴링 및 재원의 효율적 분배 를 통한 전력 계통 시스템의 신뢰도 향상을 위해서 필수적 으로 요구된다.

\footnotetext{
* 책임저자(Corresponding Author)

논문접수: 2011. 7. 9., 수정: 2011. 9. 2., 채택확정: 2011.9.15. 김세윤, 김성호: 군산대학교 전자정보공학부

(ksydiary@kunsan.ac.kr/shkim@kunsan.ac.kr)

※ 본 연구는 교육과학기술부와 한국연구재단의 지역혁신인력양성 사업으로 수행된 연구결과임.
※ 상기 논문은 제어·로봇 - 시스템학회 전북제주지부의 학술대회 에서 초안이 발표되었음.

예측 기법은 크게 통계학적 기법, 시계열 모델(time series model) 및 지능형 기법 등으로 구분될 수 있다[1]. 시계열 모델은 측정된 풍속 데이터와 통계학적 기법을 이용한 것으 로 이들 중 대표적인 것으로 벤치마킹 기법으로 널리 사용 되고 있는 ARMA 모델을 들 수 있다[2]. 지능형 기법은 퍼지 모델 또는 인공신경망을 이용한 것으로 일반적으로 ARMA 모델에 비해 예측 성능이 우수함이 입증된 바 있다[3].

본 연구에서는 시계열 모델보다 예측 성능이 우수한 인 공신경망 기반의 예측기법에 대해 고찰하고자 한다. 기존 대부분의 연구에서는 풍속을 기반으로 발전량을 추정하였 으나 본 연구에서는 풍향도 함께 고려함으로써 발전량 추 정 특성이 향상됨을 보이고자 하였다. 또한 추정기로 사용 될 신경망 학습의 효율을 극대화하기 위해 학습에 사용되는 풍향, 풍속 데이터에 적용될 수 있는 압축함수(compression function)를 도입하였다. 본 연구에서 제안된 전력추정기법 의 유용성 확인을 위해 군산 비웅항에 설치되어 있는 Vestas사의 $850 \mathrm{KW}$ 풍력발전기로부터의 실제 측정 데이터 를 기반으로 시뮬레이션을 수행하였다.

\section{II. 바람의 특성}

바람의 특성은 곯임없이 변화한다. 어느 특정 순간에 어 떤 곳의 풍황 특성을 안다고 해서, 그 다음 순간의 바람 특 성이 단정적으로 결정되지 않는다. 단지, 통계적인 방법을 활용하여 바람의 특성을 예측하는 것이 가능할 뿐이다. 바 람의 통계적 특성에 대한 연구는 1957년 van der Hoven에 의한 것이 주로 사용되고 있다. 그의 연구결과에 의하면, 바람은 지구상의 어느 곳이나 그립 1 과 유사한 풍속 에너 지 스펙트럼을 갖게 된다.

그림 1 의 수평축은 단위 시간당 바람 변화의 빈도수, $f$ (cycles/hour)를 나타내며, 수직축은 풍속의 파워 스펙트 럽 밀도(PSD: Power Spectral Density), $S_{v v}(f)$ 에 $f$ 를 곱한 양이다. 그립에서 보듯이 3 개의 피크가 존재한다. 첫 번째 


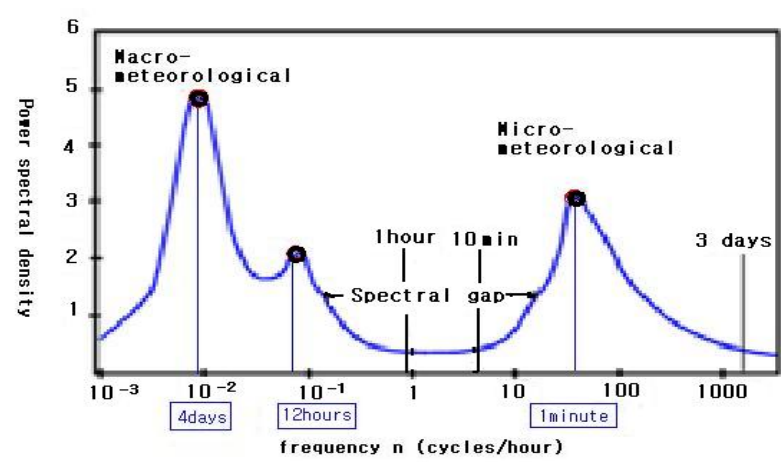

그림 1. Van der Hoven의 바람 특성 스펙트럽.

Fig. 1. The Van der Hoven wind spectrum.

피크는 $f=10^{-2}$ cycles/hour의 빈도로 변하는 바람성분으 로 이를 환산하면, 대략 4 일 주기로 변화하는 풍속으로 기 압골 영향으로 발생되는 바람 성분을 나타낸다.

두 번째 피크는 $f=0.9 \times 10^{-1}$ cycles/hour, 즉 12시간 주기의 바람 성분을 나타내는데, 낮과 밤의 기온변화에 따른 영향에 의한 것이다. 세 번째 피크는 $f=50$ cycles/hour, 다시 말해 1 분 주기로 변하는 난류(turbulence) 성분을 의미 한다. 일반적으로 풍황해석에서 10 분을 기본 단위로 하여 풍향이나 풍속, 또는 난류 강도(turbulence intensity)등을 측 정하고 있다. 10 분 주기는 그립에서 6cycles/hour에 해당 하며, 10 분 단위로 풍황의 통계학적 특성을 고려하면, 난류 의 특성을 포함하여 고찰하는 것이 가능하게 된다. 이러한 난류 성분은 제어 특성의 변화, 구조물의 잔류 진동 등에 영향을 미치기 때문에 풍력터빈 시스템의 성능을 평가하는 데 매우 중요한 요소가 된다.

\section{III. 인공신경망 기법}

인공신경망은 인간의 뇌를 모방하여 구현한 것으로 신경 세포의 정보처리 및 전달과정과 유사하다. 인공신경망은 그 립 2와 같이 입력충, 출력충 및 하나 이상의 은닉충으로 구 성된다. 각 충은 다수의 유닛 혹은 뉴런으로 구성되어 있고 각 층의 뉴런은 수정 가능한 연결 가중치로 다른 층의 뉴 런과 연결되어 있다. 지도학습법(supervised learning rule)을 따르는 인공신경망은 입력층에 훈련 패턴을 제시하고 신경 망 내의 연산을 거쳐 출력을 산출하는 과정과 산출된 출력 값과 원하는 목표값이 일치하도록 신경망내의 연결 가중치 의 값을 수정하는 과정을 거친다. 전자의 과정을 피드포워

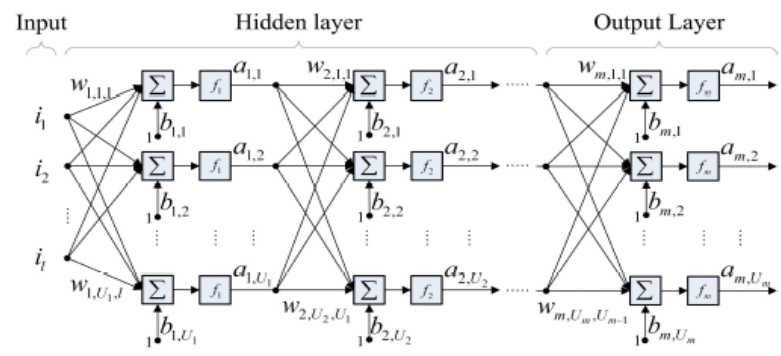

그림 2. 인공신경망의 구조.

Fig. 2. The structure of neural networks.
드 연산(feedforward operation), 후자의 과정을 학습(learning) 이라 한다.

그립 2 는 $l$ 개의 입력과 $U_{m}$ 개의 출력을 갖는 다층 구조 의 인공신경망을 나타내며 총 m-1 개의 은닉층과 한 개의 출력층 으로 구성되어 있다. 식 (1)은 그립 2에 도시된 다 층 구조의 각 계층별 입출력 관계를 나타내고 있다. 뉴런 모델의 가중치 행렬 $\left(W_{n}\right)$ 과 바이어스 벡터 $\left(b_{n}\right)$ 의 각 요소는 Hebbian 학습법, Widrow-Hoff 학습법, 역전파 알고리즘 (back-propagation algorithm) 등에 의한 학습을 통하여 최적 화 된다[5].

$$
\begin{aligned}
a_{1} & =f_{1}\left(W_{1} I+b_{1}\right) \\
a_{2} & =f_{2}\left(W_{2} a_{1}+b_{2}\right) \\
& \vdots \\
a_{m} & =f_{m}\left(W_{m} a_{m-1}+b_{m}\right)
\end{aligned}
$$

$$
\text { 여기서 } \begin{aligned}
a_{n-1} & =\left[\begin{array}{llll}
a_{n-1,1} & a_{n-1,2} & \cdots & a_{n-1, U_{n-1}}
\end{array}\right]^{T}, \\
W_{n} & =\left[\begin{array}{cccc}
w_{n, 1,1} & w_{n, 1,2} & \cdots & w_{n, 1, U_{n-1}} \\
w_{n, 1,1} & w_{n, 1,2} & \cdots & w_{n, 1, U_{n-1}} \\
\vdots & \vdots & \ddots & \vdots \\
w_{n, 1,1} & w_{n, 1,2} & \cdots & w_{n, 1, U_{n-1}}
\end{array}\right], \\
a_{0} & =I=\left[\begin{array}{llll}
i_{1} & i_{2} & \cdots & i_{l}
\end{array}\right]^{T}, \\
b_{n} & =\left[\begin{array}{llll}
b_{n, 1} & b_{n, 2} & \cdots & b_{n, U_{n}}
\end{array}\right]^{T}
\end{aligned}
$$

이다. 이때, $n=1,2, \cdots, m$ 이고 $U_{0}=l$ 이다.

\section{IV. 시뮬레이션 고찰}

본 장에서는 인공신경망을 기반으로 하는 전력 예측기법 에 대해 고찰하고자 한다. 전력 예측기는 입력으로 풍속, 풍향 정보를 사용하고 출력으로 발전량을 사용한다. 실험에 사용된 데이터는 군산 비응도동 군장산업단지 내 설치된 $850 \mathrm{KW}$ 급 풍력발전기로부터의 데이터를 이용 하였다.

비응도 군산 풍력발전소는 2002년에 1호기를 시작하여 2007년에 10호기를 마지막으로 완공되었으며, 덴마크 NEG-Micon사의 750KW 모델(NM48) 6기와 덴마크 VESTAS 사의 $850 \mathrm{KW}$ 모델(V52) 4 기로 구성되어 있다.

각 발전기의 허브까지의 높이는 $45 \mathrm{~m}$ 와 $49 \mathrm{~m}$ 이며 블레이 드의 수는 3 개이고 Cut-in wind speed는 $4 \mathrm{~m} / \mathrm{s}$, rated wind speed는 $16 \mathrm{~m} / \mathrm{s}$, Cut-out wind speed는 $25 \mathrm{~m} / \mathrm{s}$ 이다. 또한 NM48 은 스톨제어방식이고 V52는 피치제어방식으로 운전되고 있 으며 각 풍력발전기의 제원을 나타내면 표 1과 같다.

\section{표 1. 비응도 풍력발전기 제원.}

Table 1. Specification of wind turbine installed in Bee-eung wind farm.

\begin{tabular}{|c|c|c|}
\hline & NM48 & V52 \\
\hline Nominal output & $750 \mathrm{KW}$ & $850 \mathrm{KW}$ \\
\hline Hub Height & $45 \mathrm{~m}$ & $49 \mathrm{~m}$ \\
\hline Rotor Diameter & $48 \mathrm{~m}$ & $52 \mathrm{~m}$ \\
\hline Number of Blades & 3 & 3 \\
\hline Cut-in wind speed & $4 \mathrm{~m} / \mathrm{s}$ & $4 \mathrm{~m} / \mathrm{s}$ \\
\hline Nominal wind speed & $16 \mathrm{~m} / \mathrm{s}$ & $16 \mathrm{~m} / \mathrm{s}$ \\
\hline Cut-out wind speed & $25 \mathrm{~m} / \mathrm{s}$ & $25 \mathrm{~m} / \mathrm{s}$ \\
\hline
\end{tabular}




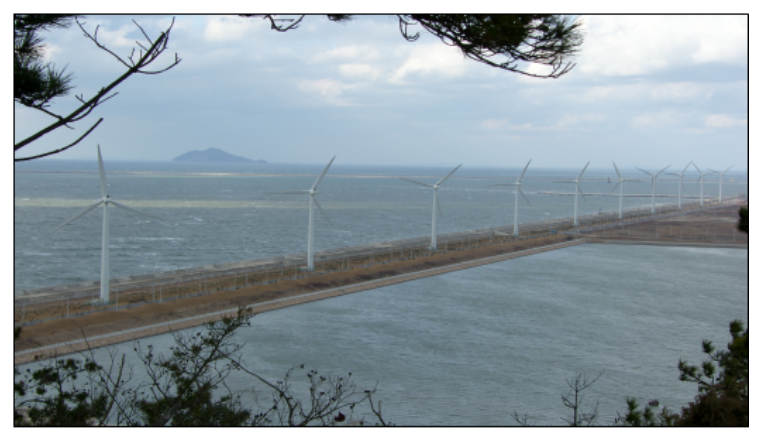

그림 3. 비응도 풍력발전 단지 전경.

Fig. 3. Landscape of Bee-eung wind farm.

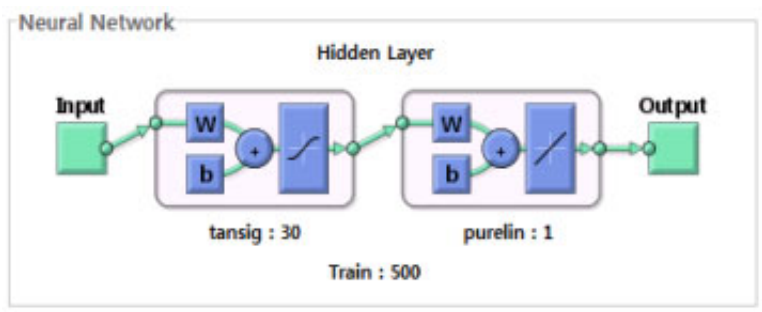

그림 4. 실험에 사용한 인공 신경망 구조.

Fig. 4. Structure of neural network.

\section{1. 사용된 인공신경망의 구조}

인공신경망의 학습을 위해 Matlab에서 제공하는 neural network toolbox를 사용하였으며, 입력층, 은닉층 및 출력충 은 각각 $2,2,1$ 의 뉴런으로 구성되었다. 또한 신경망의 학 습을 위한 반복횟수는 500 을 사용하였다.

2. 실측 데이터

군산 비응도의 풍력 발전기 7호기 $(850 \mathrm{KW})$ 의 2011년 2월 26 일부터 동년 3 월 29 일까지의 10 분 평균 풍속, 풍향 및 발 전량을 나타내면 그립 $5,6,7$ 과 같다. 데이터는 각각 4464 개가 있으며 신경망의 학습을 위해 사용될 데이터는 처음 4000개이며, 464개의 데이터는 학습된 신경망의 예측 성능 의 확인을 위해 사용하였다.

상기와 같은 데이터를 이용하여 신경망을 학습하였다. 학습에 사용된 입력 데이터는 $\mathrm{k}$-번째의 풍속 데이터 및 풍 향 데이터이며 출력 데이터는 $\mathrm{k}+1$ 번째의 전력 데이터를 사용하였다.

학습이 진행됨에 따라 출력 오차의 변화양상을 나타내면 그림 8과 같다.

학습이 완료된 신경망에 학습에 사용되지 않은 464개의 데이터를 입력하여 예측된 데이터와 실제 데이터를 나타내 면 그림 9 와 같으며 이들 간의 예측 오차를 나타내면 그림 10 과 같다.

\section{3. 학습 데이터의 압축}

인공신경망의 학습시 사용되는 데이터에는 학습에 비효 율적인 데이터가 포함되어 있기 때문에 인공신경망의 학습 효율 및 성능이 저하되는 문제점이 발생된다. 이에 본 연구 에서는 이들 문제점을 해결하기 위해 학습시 사용되는 데 이터를 가공하고자 하였다. 인공신경망의 학습의 효율성확 대를 위해 채택한 방법은 다음과 같다.

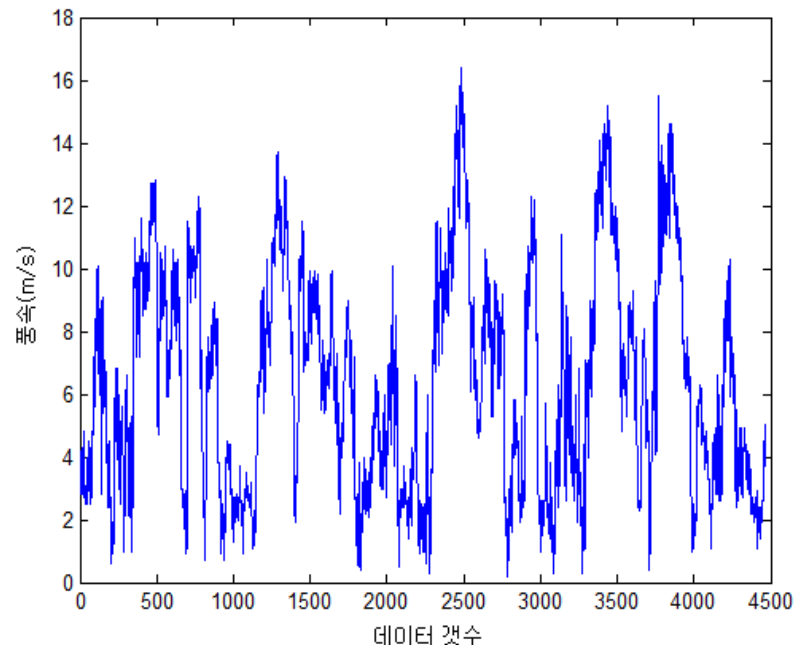

그림 5. 풍속 데이터.

Fig. 5. Actual wind speed.

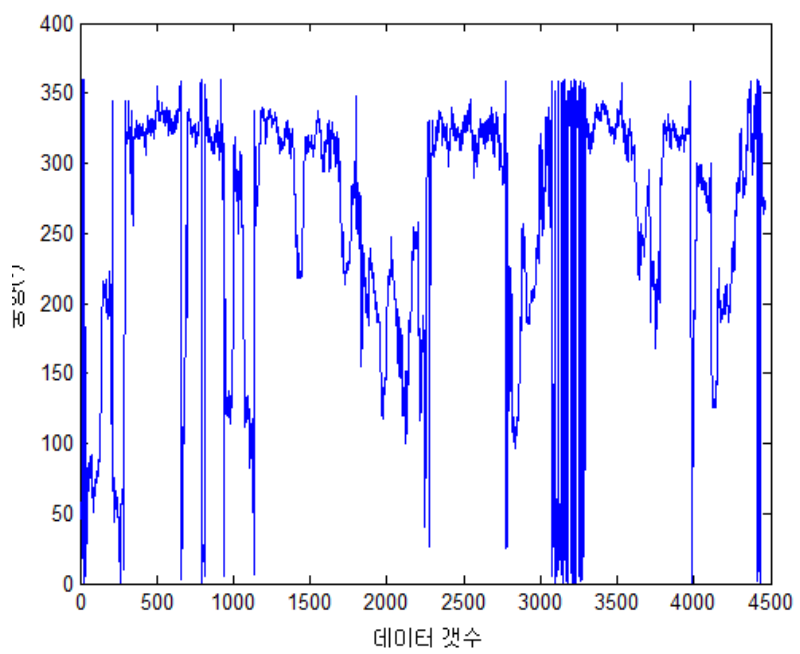

그림 6. 풍향 데이터.

Fig. 6. Actual wind direction.

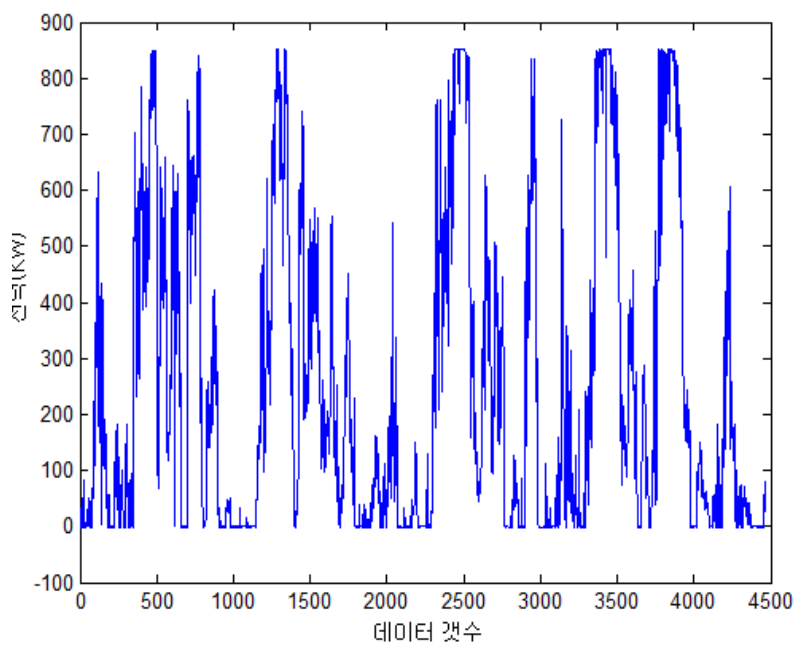

그립 7. 발전량데이터.

Fig. 7. Actual generated power. 


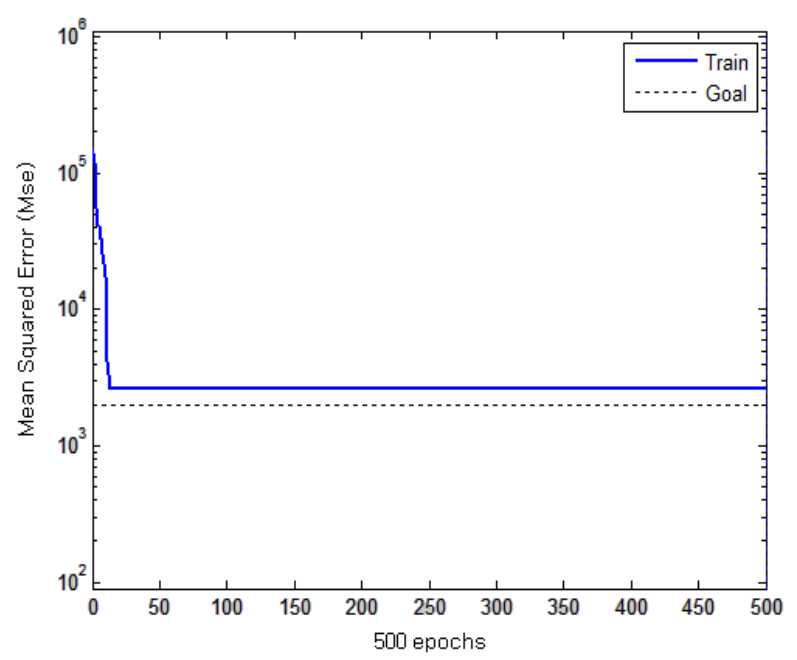

그림 8. 학습단계에 따른 오차 변화율.

Fig. 8. Error change rate.

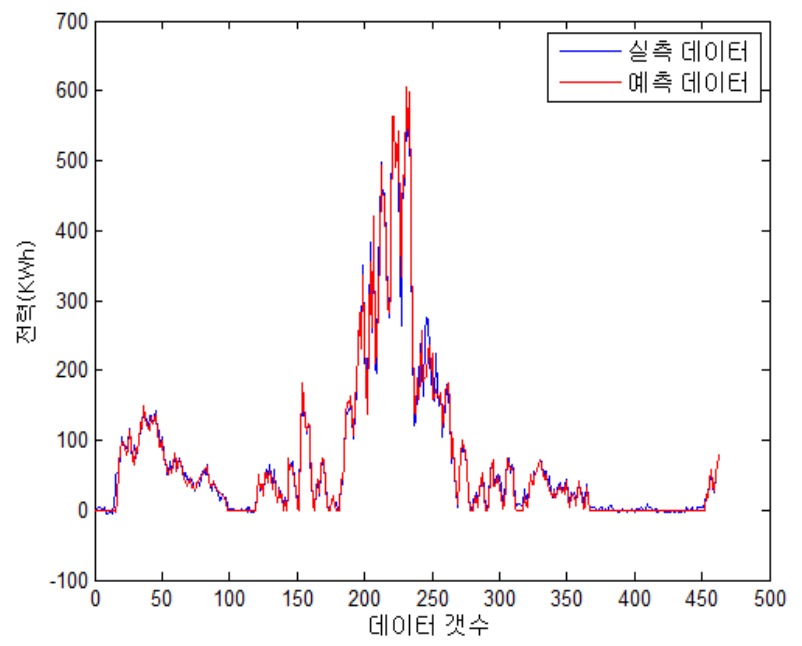

그림 9. 실측 데이터와 예측 데이터.

Fig. 9. Predicted and actual generated power.

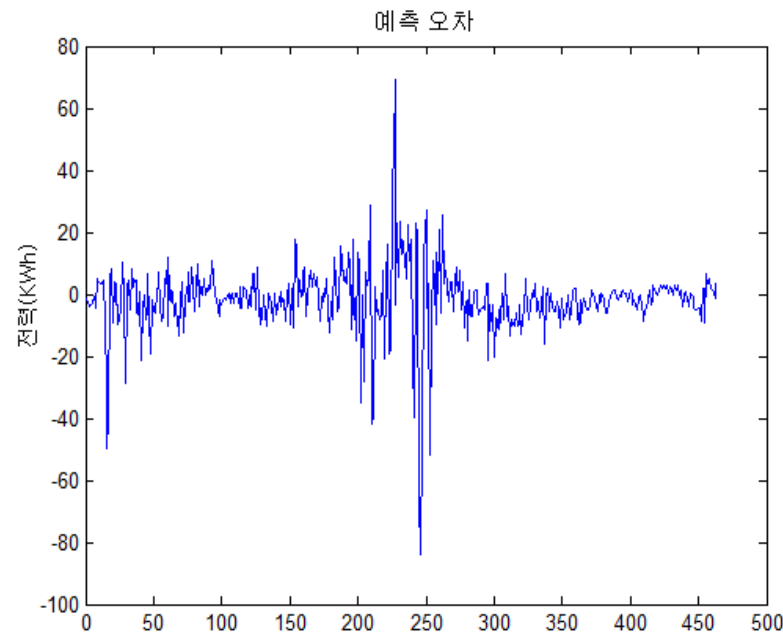

그립 10. 실측 데이터와 예측 데이터간의 오차.

Fig. 10. Error between actual and predicted generated power.

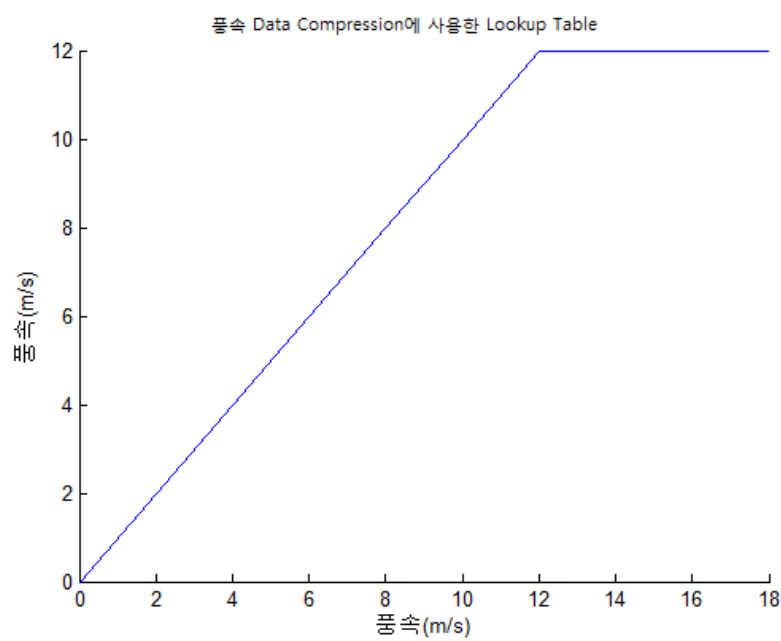

그림 11. 풍속 데이터의 압축을 위한 압축함수.

Fig. 11. Compression function used for wind speed.

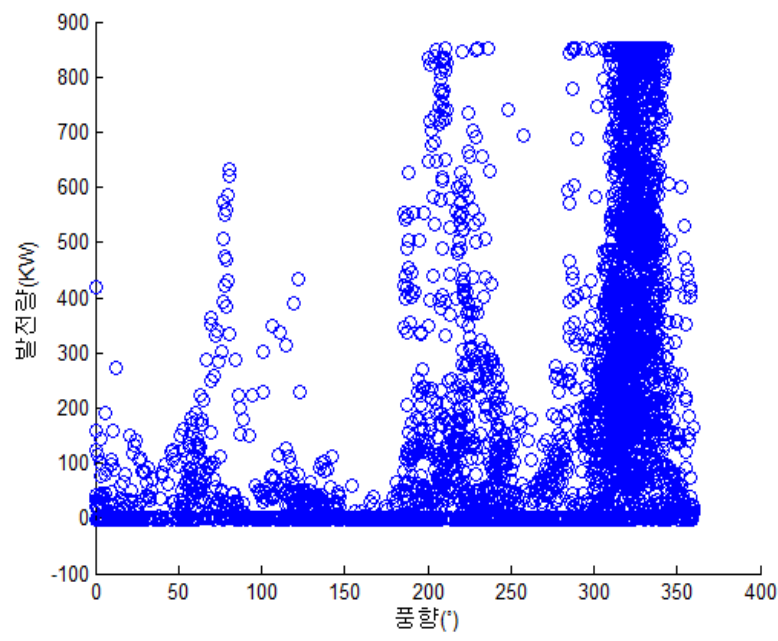

그림 12. 풍향에 따른 발전량 그래프.

Fig. 12. Influence of wind power generation according to wind direction.

그림 5 의 풍속 데이터로부터 $12 \mathrm{~m} / \mathrm{s}$ 가 넘어가면 피치제어 를 통하여 발전기의 정격 출력인 $850 \mathrm{KW}$ 를 얻어내기 때문 에 학습에 사용되는 풍속은 최대 $12 \mathrm{~m} / \mathrm{s}$ 까지의 정보가 유용 함을 알 수 있다. 따라서 본 연구에서는 그림 11 과 같은 풍 속 데이터 압축 함수를 도입하고자 하였다.

풍향의 경우는 그림 12 에서 알 수 있듯이 바람이 부는 방향에 따라 발전이 크게 되는 방향이 존재하기 때문에 발 전량이 큰 풍향에 가중치를 두어 학습 데이터를 만드는 것 이 유용함을 알 수 있다. 따라서 본 연구에서는 그립 13과 같은 풍향 데이터에 적용될 수 있는 압축함수를 도입하고 자 하였다.

전절의 인공신경망 학습의 경우와 마찬가지로 압축된 데 이터를 인공 신경망의 학습데이터로 사용하였다. 학습에 사 용된 입력 데이터는 $\mathrm{k}$-번째 압축함수를 통해 얻어진 풍속 데이터와 풍향 데이터이며 출력 데이터는 $\mathrm{k}+1$ 번째 전력 데이터이다. 


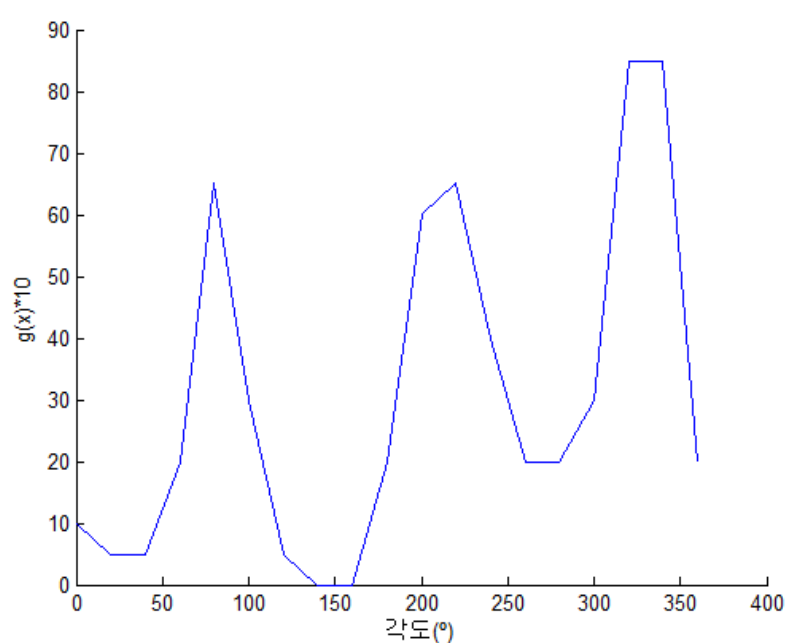

그림 13. 풍향 데이터의 압축을 위한 압축 함수.

Fig. 13. Compression function used for wind direction.

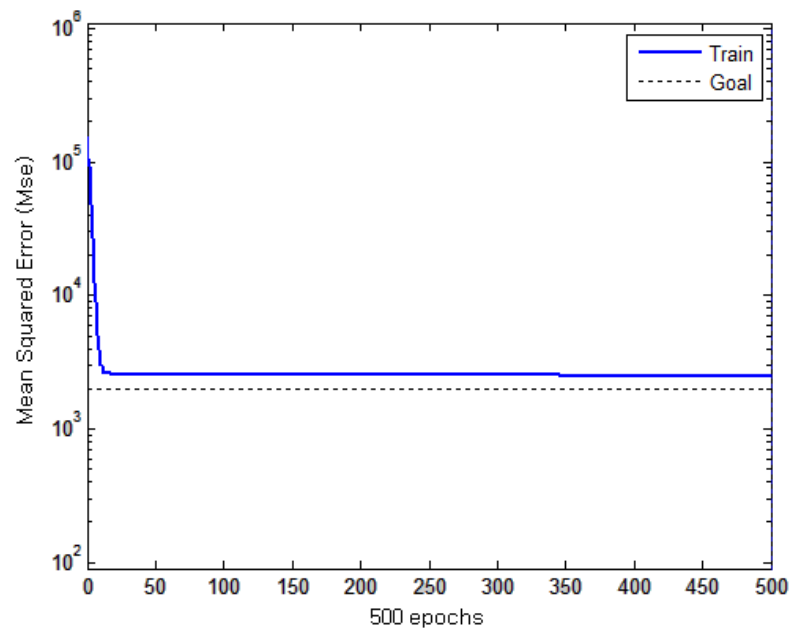

그림 14. 압축된 데이터를 사용할 경우의 학습단계에서의 오차 변화율.

Fig. 14. Error change rate in case of proposed scheme.

학습이 진행됨에 따라 츨력 오차의 변화양상을 나타내 면 그립 14 와 같다. 그립 11,13 과 같이 주어진 압축함수를 통해 변환된 풍속, 풍향 데이터를 나타내면 그립 15,16 과 같다.

압축함수를 이용하여 4000개의 데이터를 학습시켰으며 학습이 잘 수행되었는지 학습 데이터를 학습이 완료된 인 공신경망에 입력하였을 경우의 출력 특성을 나타내면 그림 17 과 같다.

전절의 경우와 마찬가지로 압축된 학습데이터에 의해 학 습된 인공신경망의 전력예측 특성을 알아보기 위해 하습에 사용되지 않았던 464개의 데이터에 대한 예측 성능을 나타 내면 그림 18 과 같으며 이의 예측 오차를 나타내면 그림 19 와 같다.

압축합수를 이용하여 변환된 풍속, 풍햑 데이터를 사웅 하였을 경우의 전력 예측오차와 압축함수를 사용하지 않았 을 경우의 전력 예측오차를 나타내면 그림 20 과 같다.

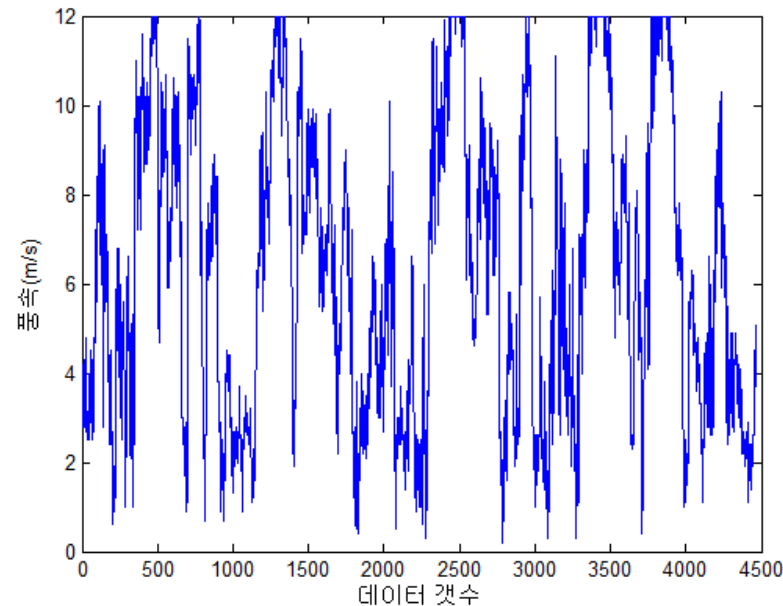

그림 15. 압축함수에 의해 변환된 풍속 데이터.

Fig. 15. Wind speed data obtained by applying compression function.

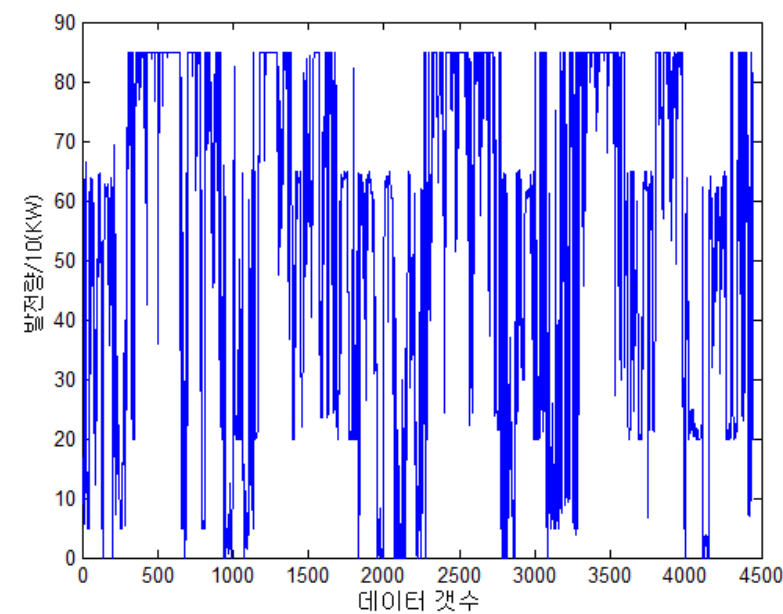

그림 16. 압축함수에 의해 변환된 풍향 데이터.

Fig. 16. Wind direction data obtained by applying compression function.

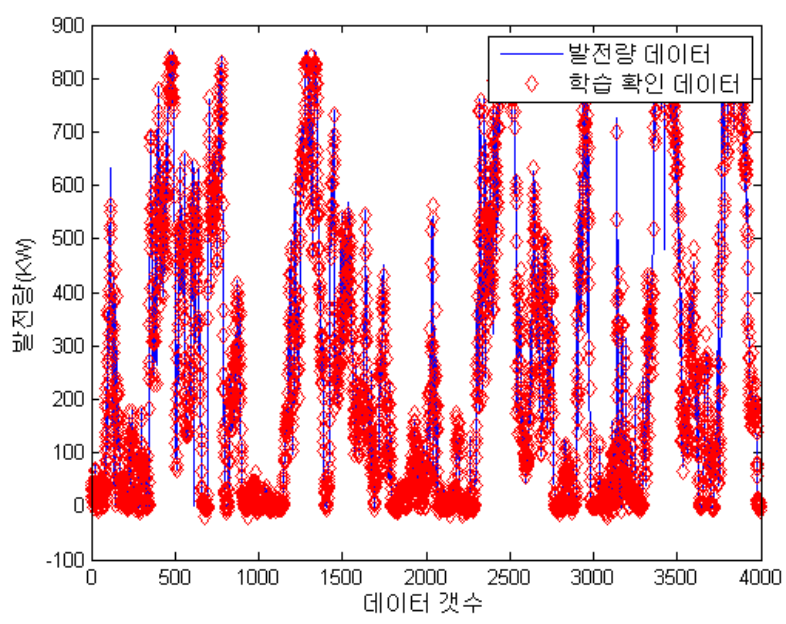

그림 17. 학습된 인공신경망의 예측 특성.

Fig. 17. Prediction characteristic of trained neural network. 


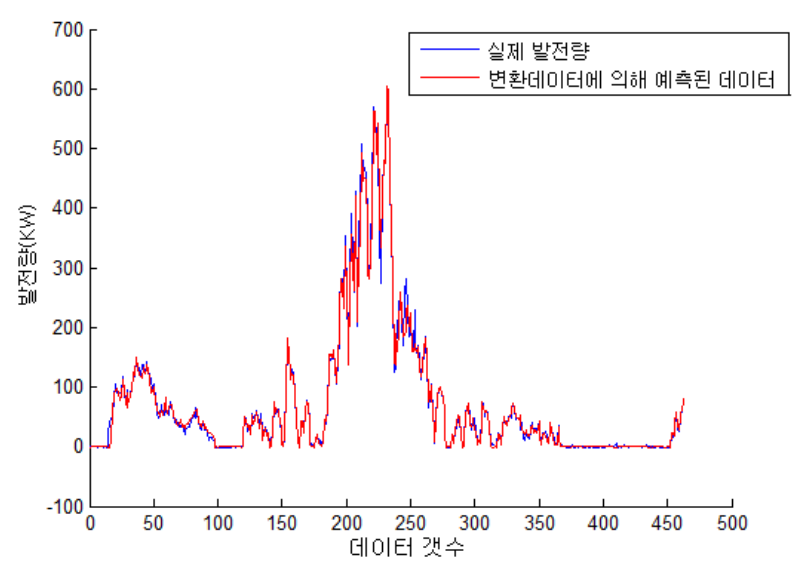

그림 18. 압축 데이터를 사융한 경우의 예측 특성.

Fig. 18. Prediction characteristics in case of introducing compression function.

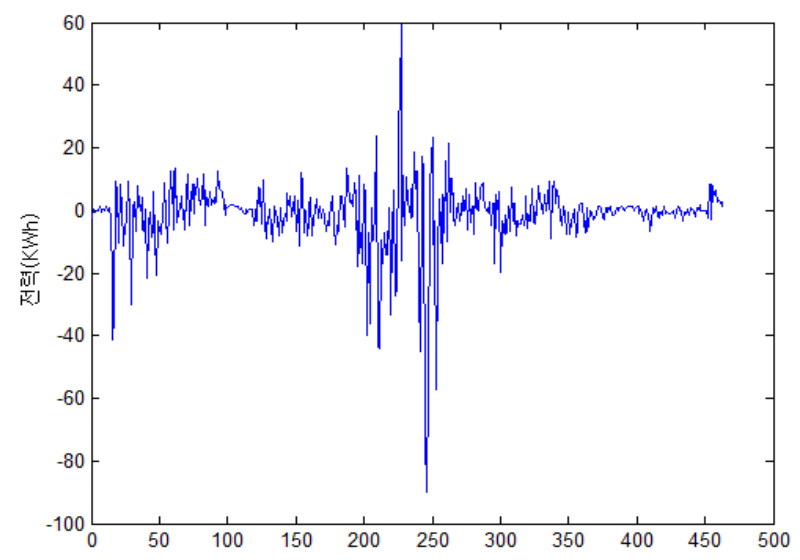

그림 19. 압축된 데이터를 사용할 경우의 예측 오차.

Fig. 19. Prediction error in case of introducing compression function.

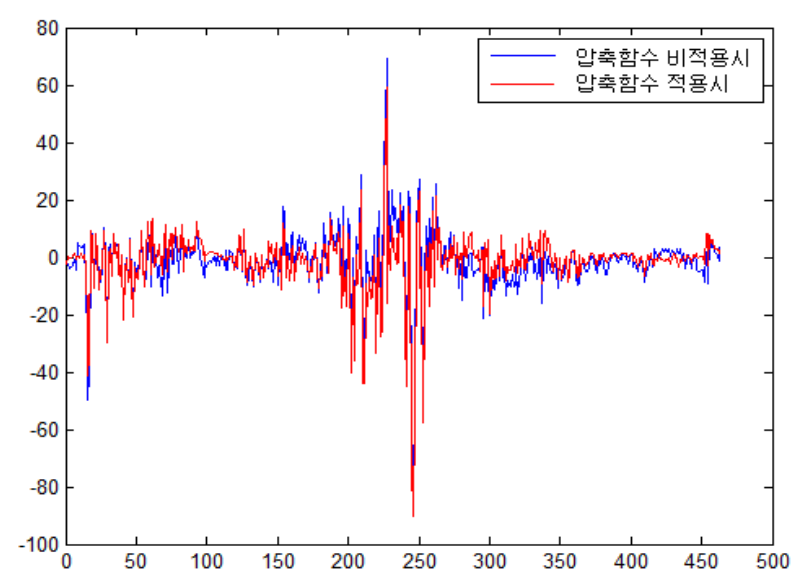

그림 20. 전력 예측 오차.

Fig. 20. Prediction error.

그림 20에서 알 수 있듯이 압축합수를 도입하여 풍속, 풍향 데이터를 변환하고 이를 학습에 이용할 경우 전력 예 측 오차가 상당히 줄어듦을 알 수 있다.

\section{V. 결론}

본 연구에서는 신경망 기반의 전력 예측기법에 대해 고 찰하였으며 특히, 신경망의 효율적인 학습과 예측 오차의 최소화를 위해 풍속, 풍향 데이터에 적용가능한 압축함수를 도입하였다. 도입된 압축함수의 유용성을 확인하기 위해 실 제의 계측 데이터에 적용하여 봄으로써 압축함수의 유용성 을 확인할 수 있었다.

\section{참고문헌}

[1] S. S. Jo and Y. S. Son, "Time series analysis," Yulgok Publishers, 2009.

[2] J. H. Lee, "Time series analysis and applications," Freedom Academy, 2007.

[3] F. Lin, X. H. Yu, S. Gregor, and R. Irons, "Time series forecasting with neural networks," Complex Systems: Mechanism of Adaptation, pp. 245-252, 1994.

[4] S. Li, D. C. Wunsch, E. O'Hair, and M. G. Giesselmann, "Neural network for wind power generation with compressing function," Neural Networks, International Conference on, pp. 115-120, 1997.

[5] H. G. Beyer, D. Heinemann, H. Mellinghoff, K. Mönnich, and H. P. Waldl, "Forecast of regional power output of wind turbines," Proc. of the European Wind Energy Conference, Nice, France, March 1999.

[6] G. Giebel, J. Badger, I. Martí Perez, P. Louka, G. Kallos, and A. M. Palomares, et al., "Short-term Forecasting Using Advanced Physical Modelling -," the Results of the Anemos Project, Results from mesoscale, microscale and CFD modeling. Proceedings of the European Wind Energy Conference, Athens, Greece, 27 February-2 March 2006.

[7] S. Y. Kim and S. H. Kim, "Study on the prediction of wind power generation based on artificial neural network," Journal of Institute of Control, Robotics and Systems (in Korean), pp. 31-34, 2011.

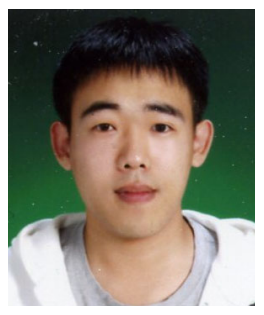

\section{김 세 윤}

2008년 군산대학교 전자정보공학부 학 사졸업. 2011년 동 대학원 석사. 관심 분야는 풍력발전, 인공신경망, 자동제 어, 소프트웨어 설계 및 개발.

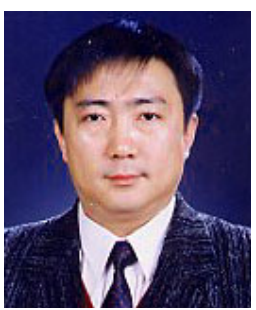

\section{김 성 호}

1984년 고려대학교 공과대학 학사졸업. 1986년 고려대학교 대학원 석사졸업. 1991년 고려대학교 대학원 박사졸업. 1988년 1990년 고려대 생산기술연구소 연구원. 1995년 1996년 Japan Hiroshima University Post-Doc. 1991년 군산대학 교 제어계측공학과 교수. 관심분야는 풍력발전, 인공 신경 망, 펴지, 센서 네트워크, 공장 자동화 및 오류검출. 